\title{
Article \\ Comparative Study of Roxarsone Reduction by Shewanella oneidensis MR-1 and Cellulomonas sp. Strain Cellu-2a
}

\author{
Anamika Khanal ${ }^{1}$, Cuong Tu Ho ${ }^{2} \mathbb{D}$, Hor-Gil Hur $^{3}$ and Ji-Hoon Lee ${ }^{1,4, *(\mathbb{D}}$ \\ 1 Department of Bioenvironmental Chemistry, Jeonbuk National University, Jeonju 54896, Korea; \\ anamika.khanal@gmail.com \\ 2 Institute of Environmental Technology, Vietnam Academy of Science and Technology, Hanoi 10072, Vietnam; \\ hotucuong@gmail.com \\ 3 School of Environmental and Earth Science, Gwangju Institute of Science and Technology, \\ Gwangju 61005, Korea; hghur@gist.ac.kr \\ 4 Department of Agricultural Convergence Technology, Jeonbuk National University, Jeonju 54896, Korea \\ * Correspondence: jhlee2@jbnu.ac.kr; Tel.:+82-63-270-2546; Fax:+82-63-270-2550
}

Citation: Khanal, A.; Ho, C.T.; Hur, H.-G.; Lee, J.-H. Comparative Study of Roxarsone Reduction by Shewanella oneidensis MR-1 and Cellulomonas sp. Strain Cellu-2a. Appl. Sci. 2022, 12, 1839. https://doi.org/ 10.3390/app12041839

Academic Editor: José Carlos

Magalhães Pires

Received: 28 December 2021

Accepted: 8 February 2022

Published: 10 February 2022

Publisher's Note: MDPI stays neutral with regard to jurisdictional claims in published maps and institutional affiliations.

Copyright: (c) 2022 by the authors. Licensee MDPI, Basel, Switzerland. This article is an open access article distributed under the terms and conditions of the Creative Commons Attribution (CC BY) license (https:// creativecommons.org/licenses/by/ $4.0 /)$.

\begin{abstract}
Roxarsone, an organoarsenic compound, has been used extensively as an additive in poultry feed to promote animal growth. Although roxarsone is moderately toxic, it can be converted into more toxic compounds upon exposure to the environment, resulting in human health risks. This article reports on a comparative study of roxarsone reduction by fermentative, anaerobic Cellulomonas sp. Cellu-2a and a widely distributed metal-reducing bacterium, Shewanella oneidensis MR-1. The strain Cellu-2a showed a faster roxarsone reduction capability by fermentative growth than by MR-1 in anaerobic respiration. With an environmentally relevant mineral, hydrous ferric oxide (HFO) included in the incubations, there was a rather rapid abiotic (indirect, heterogeneous) reduction of roxarsone by the solid phase Fe(II) in HFO generated by reduction of Fe(III) of HFO by MR-1, while still direct reduction was major reaction by Cellu-2a even with HFO. This study provides evidence of direct and/or indirect bacterial reduction of roxarsone in fermentative conditions as well as in anaerobic respiration conditions, at exposure to the environment, which would assist understanding of environmental behaviors of roxarsone in biological settings with HFO, a naturally occurring ubiquitous mineral class.
\end{abstract}

Keywords: fermentative reduction; indirect reduction; organoarsenic compound; bacterial degradation

\section{Introduction}

Organoarsenic compounds have been implemented in a variety of industries: As pesticides, poultry feed additives, herbicides, fungicides, etc. Despite their extensive use, the fact that they are associated with arsenic cannot be neglected for their toxicity due to their speciation. Among organoarsenic compounds, roxarsone (3-nitro 4-hydroxyphenyl arsonic acid) has been used extensively on poultry farms as a feed additive for the promotion of chicken growth $[1,2]$. Poultry houses and litter are known to be the main source for the accumulation and spread of roxarsone in soil and water resources [3]. Roxarsone has also been used as an anticoccidial agent [4]. The use of this compound has been banned by many countries such as the USA, Canada, Australia, and the EU. In general, these applications are declining in step with growing concerns about their impact on the environment and human health, but roxarsone and other phenylarsonic acid derivates are still used in many parts of Asia and in South American countries [5,6].

Roxarsone is highly soluble in water and hence its capacity for mobility in the environment is also higher. In turn, the chances of its contaminating the environment via transport from soil to groundwater are high [3]. Roxarsone can be converted into toxic products such as inorganic arsenic species upon exposure to the environment, resulting 
in human health risks [7]. Thus, monitoring these types of arsenic-based compounds and the microbes responsible for their transformation in the environment is essential from an environmental as well as a health perspective.

Researchers have reported that the compounds related to the transformation of roxarsone in the environment range from soil and water to a list of more specific compounds: Arsenite, arsenate, dimethylarsinic acid (DMA), monomethylarsonic acid (MMA), and 3-amino-4-hydroxyphenylarsonic acid (3-AHPAA) with the facile reduction of a nitro group [3,7-10]. Roxarsone transformation may occur through biotic or abiotic processes [11]. Moreover, several studies have shown that roxarsone can be adsorbed onto iron oxides forming immobilized arsenic compounds, and this can control the mobility of roxarsone from soil to groundwater and thus minimize its pollution [12-14]. In addition, it has also been reported that Shewanella oneidensis MR-1, a widely distributed metal-reducing bacterium, facilitated the reduction of roxarsone [15]. Other microbes such as Bacillus spp., Paenibacillus spp., Arthrobacter spp., Lysobacter spp., and Alkaliphilus spp. have also been reported to be involved in the degradation of roxarsone, especially in brown soil [16]. Recently, the biotransformation of roxarsone by the aerobic soil bacterium Enterobacter sp. CZ-1 has also been reported [17]. Even though the biotic, as well as abiotic degradation and speciation of roxarsone in aerobic and anaerobic conditions, have been studied, the information on the microorganisms responsible for the reduction in anaerobic conditions is limited. The main objectives of this study were to assess reduction of roxarsone in anaerobic conditions by Cellulomonas sp. strain Cellu-2a in fermentation condition with or without hydrous ferric oxide (HFO), a class of naturally occurring ubiquitous minerals, and to compare the direct and indirect reduction of roxarsone with the extensively studied S. oneidensis MR-1.

\section{Materials and Methods}

\subsection{Preparation of Enrichment Media}

The modified freshwater (FW) medium was prepared with the following components (in g/L): $\mathrm{KH}_{2} \mathrm{PO}_{4}(0.6), \mathrm{NH}_{4} \mathrm{Cl}(0.3), \mathrm{MgCl}_{2} \cdot 6 \mathrm{H}_{2} \mathrm{O}(0.4)$, and $\mathrm{CaCl}_{2} \cdot 2 \mathrm{H}_{2} \mathrm{O}(0.1)$ [18,19]. After autoclaving and cooling, the medium (the final $1 \mathrm{~L}$ ) was supplemented with $30 \mathrm{~mL}$ of bicarbonate solution $\left(84 \mathrm{~g} / \mathrm{L} \mathrm{NaHCO}_{3}\right), 1 \mathrm{~mL}$ of selenite-tungstate solution $(0.5 \mathrm{~g} / \mathrm{L} \mathrm{NaOH}$, $3 \mathrm{mg} / \mathrm{L} \mathrm{Na}_{2} \mathrm{Se}_{5} \mathrm{H}_{2} \mathrm{O}$, and $4 \mathrm{mg} / \mathrm{L} \mathrm{Na}_{2} \mathrm{WO}_{4} 2 \mathrm{H}_{2} \mathrm{O}$ ), $1 \mathrm{~mL}$ of trace element solution, $1 \mathrm{~mL}$ of vitamin solution, and $1 \mathrm{~mL}$ of vitamin $\mathrm{B} 12$ solution (50 $\mathrm{mg} / \mathrm{L}$ cyanocobalamine).

The trace element solution contained (g/L) nitrilotriacetic acid (12.8), $\mathrm{FeCl}_{2} \cdot 4 \mathrm{H}_{2} \mathrm{O}(2)$, $\mathrm{CoCl}_{2} \cdot 6 \mathrm{H}_{2} \mathrm{O}(0.19), \mathrm{MnCl}_{2} \cdot 2 \mathrm{H}_{2} \mathrm{O}(0.1), \mathrm{ZnCl}_{2}(0.07), \mathrm{H}_{3} \mathrm{BO}_{3}(0.006), \mathrm{NiCl}_{2} \cdot 6 \mathrm{H}_{2} \mathrm{O}(0.024)$, $\mathrm{CuCl}_{2} \cdot 2 \mathrm{H}_{2} \mathrm{O}(0.002)$, and $\mathrm{Na}_{2} \mathrm{MoO}_{4} \cdot 2 \mathrm{H}_{2} \mathrm{O}(0.036)$. The vitamin solution contained $(\mathrm{mg} / \mathrm{L})$ 4-aminobenzoic acid (40), D(+)-biotin (10), nicotinic acid (100), calcium $\mathrm{D}(+)$-panthothenate (50), pyridoxine dihydrochloride (150), and thiamine chloride dihydrochloride (100) in sodium phosphate buffer (10 mM; $\mathrm{pH} 7.1)$ [20]. The $\mathrm{pH}$ of the media was adjusted to 6.8-6.9 by using sterile diluted $\mathrm{HCl}$ or $\mathrm{Na}_{2} \mathrm{CO}_{3}$ solution. The medium was purged for 30 min with $\mathrm{N}_{2}: \mathrm{CO}_{2}(90: 10)$ gas.

\subsection{Direct Roxarsone Reduction Experiment in Anaerobic Conditions}

A dissimilatory metal-reducing bacterium, Shewanella oneidensis strain MR-1 and a fermentative $\mathrm{Cr}(\mathrm{VI})$-reducing bacterium, Cellulomonas sp. strain Cellu-2a [21] were used to assess on reduction of the organoarsenic compound, roxarsone in anaerobic conditions. In addition to $S$. oneidensis MR-1 that has been known to reduce roxarsone as the electron acceptor, Cellulomonas sp. Cellu-2a was chosen to know the potential of roxarsone degradation in the fermentative bacterial growths in comparison to the anaerobic respiration. In a $100 \mathrm{~mL}$ serum bottle containing $50 \mathrm{~mL}$ modified FW media, roxarsone was added at the final concentration of $0.1 \mathrm{mM}$ from $10 \mathrm{mM}$ stock solution, and $10 \mathrm{mM}$ lactate or $10 \mathrm{mM}$ sucrose was added as a sole carbon source for MR-1 or Cellu-2a, respectively, from $0.1 \mathrm{M}$ stock solutions. The serum bottle was sealed with a butyl rubber stopper, and a mixture of gas $\left(90 \% \mathrm{~N}_{2}: 10 \% \mathrm{CO}_{2}\right)$ was purged to the serum bottle. The cell inoculants were prepared 
by incubating the seed cultures (MR-1 or Cellu-2a) in tryptic soy broth (TSB) at $30^{\circ} \mathrm{C}$ for $16 \mathrm{~h}$ aerobically and transferring the cells at $10^{-2}(v / v)$ into the fresh TSB for another $16 \mathrm{~h}$ incubations. The harvested cells were washed by centrifugation ( $150 \mathrm{rpm}$ for $5 \mathrm{~min}$ ) and resuspension in $\mathrm{FW}$ medium and normalized to $\mathrm{OD}_{600}$ of 1.5 with $\mathrm{FW}$ medium (resulting in $2 \times 10^{9}$ cells $/ \mathrm{mL}$ ). The cells of strain MR-1 or strain Cellu-2a were inoculated to the experimental bottles at $10^{-1}(\mathrm{v} / \mathrm{v})$ at the final concentration of $2.0 \times 10^{8}$ cells $/ \mathrm{mL}$. The experiment was performed in triplicate individual incubations at $30^{\circ} \mathrm{C}$ for both strains. Abiotic control without the addition of any microorganism was also performed for both bacterial strains.

\subsection{Indirect Roxarsone Reduction Experiment in Anaerobic Conditions Using Solid Iron (HFO)}

The HFO would undergo reduction by the bacterial strains of Cellu-2a and MR-1 and the reduced solid phase Fe might act as a reductant for roxarsone reduction. Based on this idea, the indirect roxarsone reduction experiment was performed similarly as mentioned above in the direct reduction experiment, using the same conditions of the media, roxarsone concentration, and the carbon sources, but with additional inclusion of $2 \mathrm{mM}$ HFO. The experiments were performed in triplicates. Abiotic controls in both conditions were also conducted without the addition of any microorganism. The HFO solution was synthesized, and the preparation method was provided in the previous publication [21].

\subsection{Analytical Measurements}

The samples were taken at selected time points of beginning (time 0), 2 days, 5 days, 10 days, 15 days, and 30 days after incubation. The growth of the bacteria was measured by optical density at $600 \mathrm{~nm}\left(\mathrm{OD}_{600}\right)$. Roxarsone concentration was measured spectrophotometrically at a wavelength of $400 \mathrm{~nm}$ [13]. The ferrozine method was used for the measurement of iron [22]. For ferrous iron measurement, the sample was first filtered using a $0.22 \mu \mathrm{m}$ cellulose syringe filter and $1 \mathrm{~mL}$ of the filtrate was mixed with the same of $1 \mathrm{~N} \mathrm{HCl}$. For total iron measurement, hydroxylamine hydrochloride was added to the unfiltered or filtered sample to reduce all the ferric iron to ferrous iron. The measurements were conducted using the spectrophotometer at a wavelength of $562 \mathrm{~nm}$.

\section{Results and Discussion}

\subsection{Direct Roxarsone Reduction Experiment}

In the direct roxarsone reduction experiment, minor growth of the strain MR-1 was observed with lactate as a carbon source (Figure 1A). Chen et al. [15] suggested that S. oneidensis MR-1 was able to use roxarsone as a terminal electron acceptor. Therefore, it was speculated that the minimal cell growth might be due to the anaerobic respiration using roxarsone as the e-acceptor, even though experiments were not performed to confirm the usage of roxarsone as the e-acceptor by MR- 1 in this study. The concentration of roxarsone was found to decrease gradually from the initial $97.5 \mu \mathrm{M}$ to $2.6 \pm 1.2 \mu \mathrm{M}$ at 30 days in the incubations with MR-1, while in the uninoculated control the concentrations remained at similar level from 2 days to 30 days at $63.8 \mu \mathrm{M}$ (Figure 1A). For comparison, in the previous work by Chen et al. [15], roxarsone concentrations decreased much faster to undetectable levels within 5 days from the initial concentrations of 0.1 to $2.5 \mathrm{mM}$. It seems that incubation conditions might affect metabolic activities of the microbes, e.g., concentration of electron donor, which was $50 \mathrm{mM}$ in the previous work and $10 \mathrm{mM}$ in this study. During the incubations, the $\mathrm{pH}$ of the media was rather stable, ranging from 6.8 to 7.2.

In the case of the strain Cellu-2a, the maximum growth was observed up to $\mathrm{OD}_{600}$ of $0.090 \pm 0.005$ at 2 days, using sucrose as a carbon source (Figure 1B). Since the strain Cellu-2a has been reported to grow fermentatively with sucrose in the previous study [21], the rapid growth was assumed to be due to fermentation. The roxarsone concentration decreased rapidly to 5 days and reached to $16.8 \pm 1.4 \mu \mathrm{M}$ at 10 days from the initial $97.6 \pm 0.1 \mu \mathrm{M}$ (Figure 1B). In the abiotic control, no obvious reduction of roxarsone was observed throughout the incubation (Figure 1B). For comparison of both strains, it seemed 
that Cellu-2a was better for roxarsone reduction than MR-1, possibly by forming larger cell mass through fermentative growth.
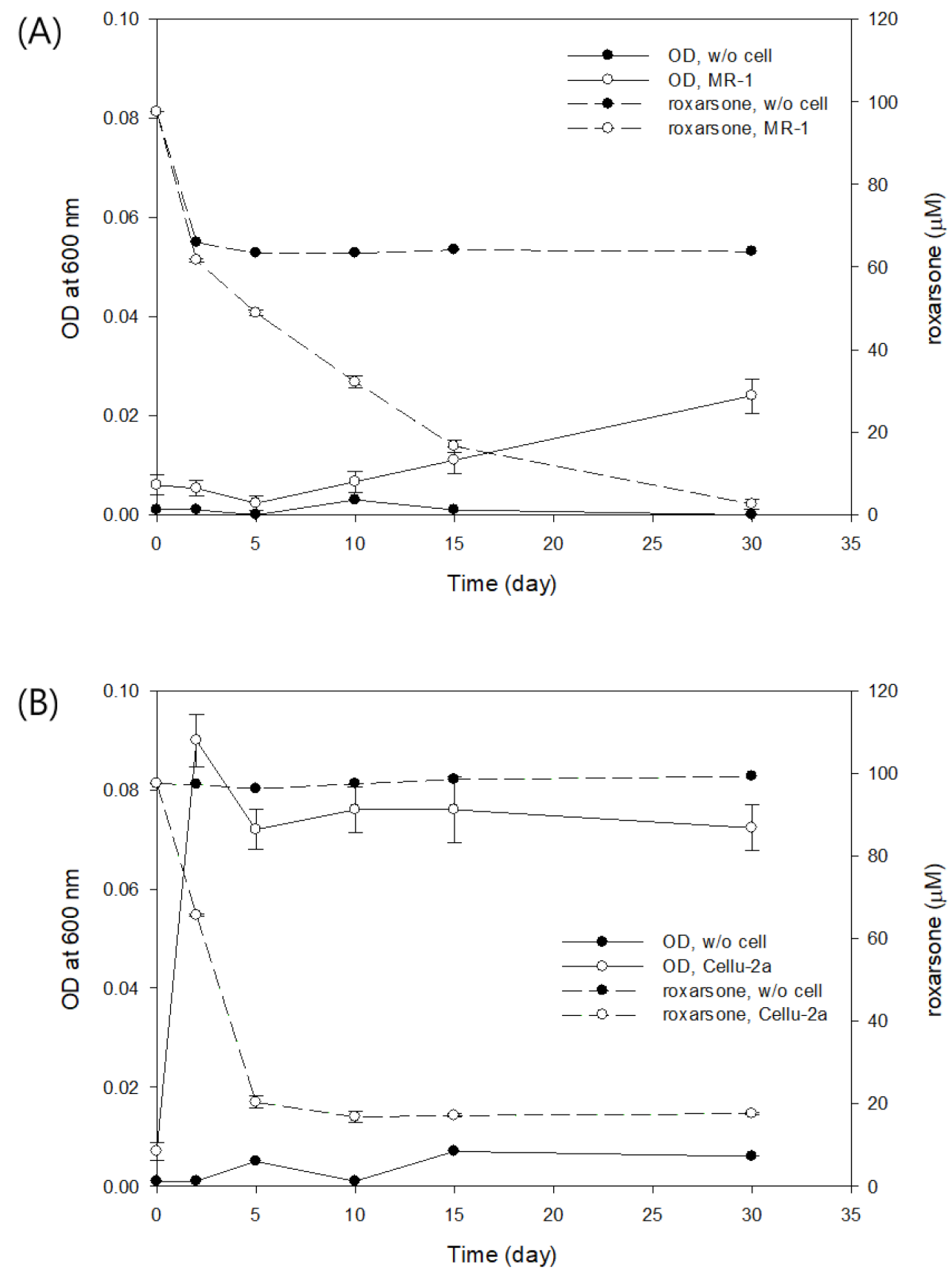

Figure 1. Optical density for bacterial cell growth and concentration of roxarsone in the direct roxarsone reduction experiments with strain MR-1 (A) and strain Cellu-2a (B).

\subsection{Indirect Roxarsone Reduction Experiment at Different Time Intervals}

The roxarsone concentration was found to decrease when HFO was included in the incubations of both strains of MR-1 and Cellu-2a (Figure 2A,B). However, the decrease patterns were different from each other. In strain MR-1, there was a lag phase of roxarsone decrease to 10 days, with a relatively rapid decrease of roxarsone from 10 days to 15 days (Figure 2A), while roxarsone decreased rather rapidly to 5 days with strain Cellu-2a (Figure 2B). It seems that there was a rather direct reduction of roxarsone in Cellu-2a incubations even with $\mathrm{HFO}$, as indicated by the similar pattern of roxarsone decrease in the direct reduction experiment (Figure 1B). 
(A)

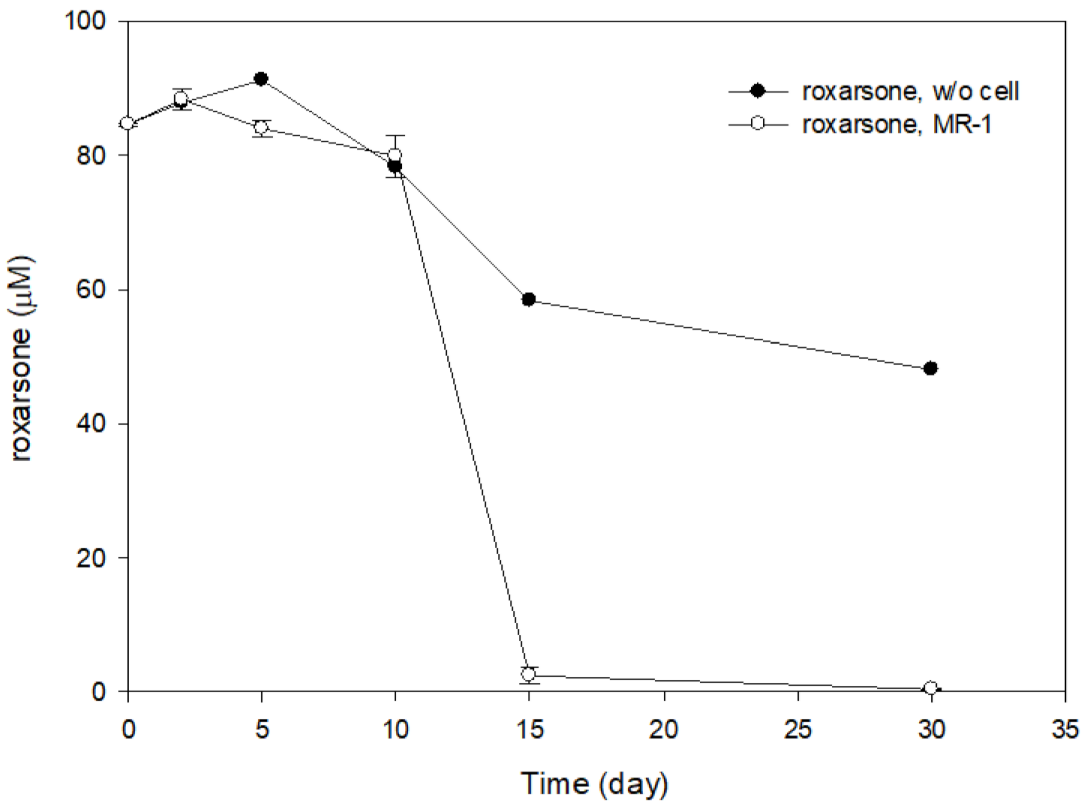

(B)

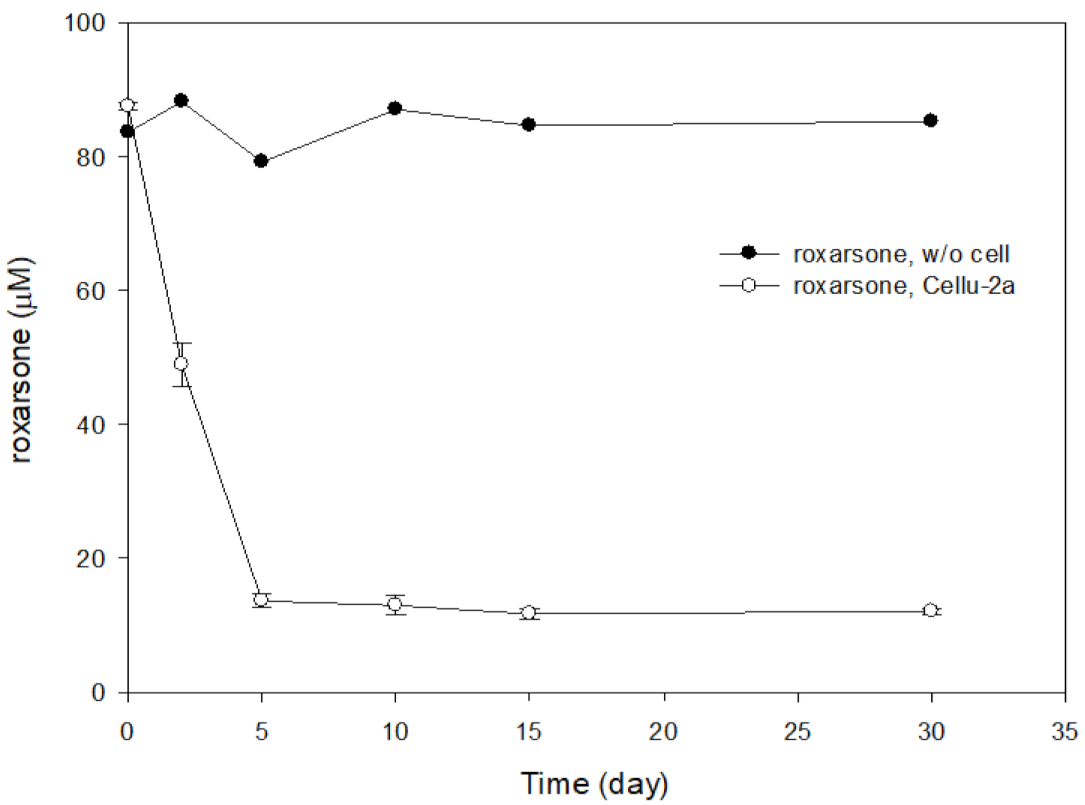

Figure 2. Roxarsone concentration in the indirect roxarsone reduction experiments with strain MR-1 (A) and strain Cellu-2a (B).

In the indirect experiment with strain MR-1, ferrous iron was found to increase up to 10 days and started to decrease gradually from 10 days to 30 days (Figure 3A). The decrease of $\mathrm{Fe}(\mathrm{II})$ may be caused by heterogeneous reduction of roxarsone on the solid $\mathrm{Fe}(\mathrm{II})$ phases of the partially reduced HFO, which is, in turn, supported by the rapid decrease of roxarsone from 10 days in Figure 2A. This suggests that the reduced Fe(II) on HFO might have acted as a reductant for roxarsone. In the previous publication by Chen et al. [15], it was reported that strain MR-1 reduced $1 \mathrm{mM}$ roxarsone almost completely within $40 \mathrm{~h}$ in the presence of soluble phase of ferric-citrate, which was much faster than the incubation without ferric-citrate. However, in this study, with solid phase Fe of HFO, the roxarsone decrease was delayed (Figure 2A), compared to the direct reduction without HFO (Figure 1A). Once reduction of HFO generated Fe(II) on solid surface of HFO, roxarsone decreased relatively rapidly (Figure $2 \mathrm{~A}$ ). From this observation, it could be speculated 
that roxarsone would react both with soluble Fe(III) and solid phase Fe(II). In addition, the differences of incubation conditions such as concentrations of electron donor, electron acceptor, and media composition might have affected the microbial metabolic activities on roxarsone reduction in both studies. In the case of strain Cellu-2a, there was no observation of decrease of the generated $\mathrm{Fe}$ (II) (Figure 3B), and ferrous iron concentration increased up to $1.91 \pm 0.06 \mathrm{mM}$, which was a near complete reduction of the initial $\mathrm{HFO}(1.96 \pm 0.03 \mathrm{mM})$ (Figure 3B). Looking at the roxarsone decrease and Fe(II) production patterns together in the Cellu-2a incubations (Figures $2 \mathrm{~B}$ and $3 \mathrm{~B}$ ), it seemed that there was no indirect reduction of roxarsone by the generated Fe(II). Instead, the strain Cellu-2a might have reduced roxarsone directly even with added $\mathrm{HFO}$ in fermentation conditions.
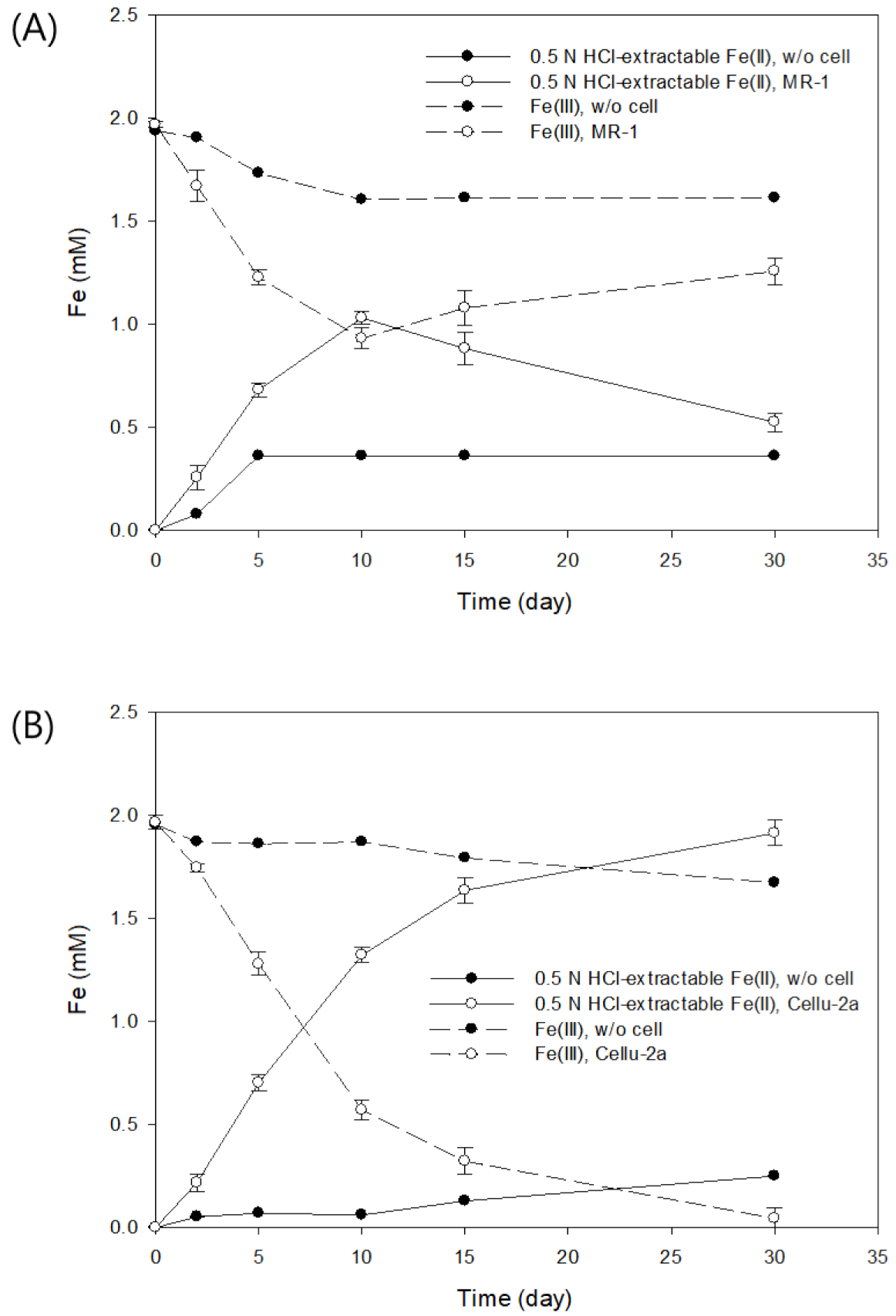

Figure 3. Concentrations of $0.5 \mathrm{~N} \mathrm{HCl}$-extractable $\mathrm{Fe}(\mathrm{II})$ and $\mathrm{Fe}(\mathrm{III})$ from $\mathrm{HFO}$ in the indirect roxarsone reduction experiments with strain MR-1 (A) and strain Cellu-2a (B). 


\subsection{Environmental Aspects}

Since roxarsone is considered to be relatively stable and inert towards degradation in the animal body, it is presumed to be and non-toxic and excreted mainly unmetabolized [23]. However, roxarsone can be rapidly converted into more toxic products, including inorganic arsenic (As), DMA, 3-AHPAA, etc., after exposure to the environment or during the composting of animal manure, leading to high environmental and human risk. From poultry urine, feces, and manures, roxarsone might be released into the environment and could be dispersed through surface water and/or groundwater, resulting in environmental pollution.

Bacterial degradation of roxarsone, as suggested in this study, might be one of the feasible solutions for alleviating the possible contamination in the environment. As the strains MR-1 and Cellu-2a showed a reduction of roxarsone concentrations in the anaerobic conditions, microorganisms performing similar anaerobic reactions in the environment may contribute to the reduction of the contaminant. In this study, strain MR-1 showed a gradual decrease of roxarsone with almost complete reduction $(0.1 \mathrm{mM})$ in 30 days (Figure 1A), while strain Cellu-2a showed a rapid direct reduction of roxarsone with decreasing approximately $80 \%$ roxarsone in 5 days under the experimental condition (Figure 1B). With HFO, a commonly found iron mineral type in the ambient environment, roxarsone decreased more rapidly than without HFO in the incubation by strain MR-1, which reduced $\mathrm{Fe}(\mathrm{III})$ in $\mathrm{HFO}$ to $\mathrm{Fe}(\mathrm{II})$, in turn, reducing roxarsone indirectly (Figure 2A). Solid phase $\mathrm{Fe}$ (II) has been known to act as an efficient reductant, providing interfacial surfaces, reactive to aqueous species of oxidants and transfer electrons between them [24]. The reduced iron Fe(II) on HFO surfaces by MR-1 might have acted as an efficient reductant for roxarsone. This type of heterogeneous reaction on solid surfaces may have facilitated a faster roxarsone decrease rather than a direct decrease by the cells.

The strain Cellu-2a indicated somewhat different patterns of roxarsone decrease, which might not have been affected by heterogenous indirect reactions of the reduced HFO. Since Cellu-2a was able to grow to much larger cell densities by sucrose fermentation than MR-1, in advance to HFO reduction, roxarsone was reduced directly by the large numbers of Cellu-2a cells. These direct and/or indirect bacterial reductions of roxarsone may be considered as main degradation reactions in appropriate environmental conditions by anaerobic cellular respiration and/or fermentation.

There is still limited information on the byproducts formed from the reduction of roxarsone by strains MR-1 and Cellu-2a. Many researchers reported that roxarsone was transformed to an aromatic amine of 3-AHPAA by a facile reduction of the nitro group and other inorganic arsenic products such as As(III) and $\mathrm{As}(\mathrm{V})$ [25-27]. Furthermore, Chen et al. [15] have reported that $S$. oneidensis MR-1 showed the transformation of roxarsone to 3-AHPAA in the presence of dissolved Fe(III). Although identification of the byproducts or metabolites was not successful, like the above previous research, it will be important to reveal the byproducts formed by strain Cellu-2a as well as MR-1 in both direct and indirect reduction conditions. This would help the understanding of environmental behaviors of roxarsone in the environment. By the assessment of bacterial degradation of roxarsone, this study provides a better idea of roxarsone behavior in anaerobic conditions by bacterial respiration and fermentation, and also by biotic and abiotic processes.

\section{Conclusions}

For more than 60 years, roxarsone has been used as a feed additive in the poultry industry and known as an arsenic contamination source of poultry and foods. In this study, roxarsone was found to be biologically degraded through anaerobic respiration as the electron acceptor by strain MR-1 and fermentation as a potential side reaction by strain Cellu-2a as well. Moreover, in the presence of environmentally relevant minerals of hydrous ferric oxides, roxarsone was reduced indirectly by the biologically reduced solid phase iron. Upon exposure of roxarsone to the environment, roxarsone may undergo biological and physicochemical degradations, affecting bioavailability, environmental toxicity, and 
persistence. Efforts to understand biological degradations, as in this study, would help better understand the environmental behaviors and fates of roxarsone.

Author Contributions: Conceptualization, J.-H.L.; investigation, A.K.; writing, A.K., C.T.H. and J.-H.L.; writing-review and editing, A.K., C.T.H., H.-G.H. and J.-H.L.; supervision, J.-H.L. All authors have read and agreed to the published version of the manuscript.

Funding: This research was supported by National Research Foundation of Korea (NRF) (Grant No. 2016R1D1A3B01012231)

Institutional Review Board Statement: Not applicable.

Informed Consent Statement: Not applicable.

Data Availability Statement: Not applicable.

Conflicts of Interest: The authors declare no conflict of interest.

\section{References}

1. Chapman, H.D.; Johnson, Z.B. Use of antibiotics and roxarsone in broiler chickens in the USA: Analysis for the years 1995 to 2000. Poult. Sci. 2002, 81, 356-364. [CrossRef] [PubMed]

2. Arai, Y.; Lanzirotti, A.; Sutton, S.; Davis, J.A.; Sparks, D.L. Arsenic speciation and reactivity in poultry litter. Environ. Sci. Technol. 2003, 37, 4083-4090. [CrossRef]

3. Garbarino, J.R.; Bednar, A.J.; Rutherford, D.W.; Beyer, R.S.; Wershaw, R.L. Environmental fate of roxarsone in poultry litter. I. Degradation of roxarsone during composting. Environ. Sci. Technol. 2003, 37, 1509-1514. [CrossRef] [PubMed]

4. Noack, S.; Chapman, H.D.; Selzer, P.M. Anticoccidial drugs of the livestock industry. Parasitol. Res. 2019, 118, 2009-2026. [CrossRef] [PubMed]

5. Nachman, K.E.; Raber, G.; Francesconi, K.A.; Navas-Acien, A.; Love, D.C. Arsenic species in poultry feather meal. Sci. Total Environ. 2012, 417-418. [CrossRef]

6. D'Angelo, E.; Zeigler, G.; Beck, E.G.; Grove, J.; Sikora, F. Arsenic species in broiler (Gallus gallus domesticus) litter, soils, maize (Zea mays L.), and groundwater from litter-amended fields. Sci. Total Environ. 2012, 438, 286-292. [CrossRef]

7. Stolz, J.F.; Perera, E.; Kilonzo, B.; Kail, B.; Crable, B.; Fisher, E.; Ranganathan, M.; Wormer, L.; Basu, P. Biotransformation of 3-nitro-4-hydroxybenzene arsonic acid (roxarsone) and release of inorganic arsenic by Clostridium species. Environ. Sci. Technol. 2007, 41, 818-823. [CrossRef]

8. Adak, A.; Mangalgiri, K.P.; Lee, J.; Blaney, L. UV irradiation and UV-H2O2 advanced oxidation of the roxarsone and nitarsone organoarsenicals. Water Res. 2015, 70, 74-85. [CrossRef]

9. Fisher, D.J.; Yonkos, L.T.; Staver, K.W. Environmental concerns of roxarsone in broiler poultry feed and litter in Maryland, USA. Environ. Sci. Technol. 2015, 49, 1999-2012. [CrossRef]

10. Liang, T.; Ke, Z.; Chen, Q.; Liu, L.; Chen, G. Degradation of roxarsone in a silt loam soil and its toxicity assessment. Chemosphere 2014, 112, 128-133. [CrossRef]

11. Bednar, A.J.; Garbarino, J.R.; Ferrer, I.; Rutherford, D.W.; Wershaw, R.L.; Ranville, J.F.; Wildeman, T.R. Photodegradation of roxarsone in poultry litter leachates. Sci. Total Environ. 2003, 302, 237-245. [CrossRef]

12. Chen, W.-R.; Huang, C.-H. Surface adsorption of organoarsenic roxarsone and arsanilic acid on iron and aluminum oxides. $J$. Hazard. Mater. 2012, 227-228, 378-385. [CrossRef] [PubMed]

13. Kwon, J.H.; Wilson, L.D.; Sammynaiken, R. Sorptive uptake studies of an aryl-arsenical with iron oxide composites on an activated carbon support. Materials 2014, 7, 1880-1898. [CrossRef] [PubMed]

14. Hu, J.; Tong, Z.; Chen, G.; Zhan, X.; Hu, Z. Adsorption of roxarsone by iron (hydr)oxide-modified multiwalled carbon nanotubes from aqueous solution and its mechanisms. Int. J. Environ. Sci. Technol. 2014, 11, 785-794. [CrossRef]

15. Chen, G.; Ke, Z.; Liang, T.; Liu, L.; Wang, G. Shewanella oneidensis MR-1-induced Fe(III) reduction facilitates roxarsone transformation. PLoS ONE 2016, 11, e0154017. [CrossRef]

16. Liu, Y.; Zhang, Z.; Li, Y.; Wen, Y.; Fei, Y. Response of soil microbial communities to roxarsone pollution along a concentration gradient. J. Environ. Sci. Health Part A 2017, 52, 819-827. [CrossRef]

17. Huang, K.; Peng, H.; Gao, F.; Liu, Q.; Lu, X.; Shen, Q.; Le, X.C.; Zhao, F.-J. Biotransformation of arsenic-containing roxarsone by an aerobic soil bacterium Enterobacter sp. CZ-1. Environ. Pollut. 2019, 247, 482-487. [CrossRef]

18. Ehrenreich, A.; Widdel, F. Anaerobic oxidation of ferrous iron by purple bacteria, a new type of phototrophic metabolism. Appl. Environ. Microbiol. 1994, 60, 4517-4526. [CrossRef]

19. Hegler, F.; Posth, N.R.; Jiang, J.; Kappler, A. Physiology of phototrophic iron(II)-oxidizing bacteria: Implications for modern and ancient environments. FEMS Microbiol. Ecol. 2008, 66, 250-260. [CrossRef]

20. Widdel, F.; Pfennig, N. Studies on dissimilatory sulfate-reducing bacteria that decompose fatty acids. Arch. Microbiol. 1981, 129, 395-400. [CrossRef] 
21. Khanal, A.; Hur, H.-G.; Fredrickson, J.K.; Lee, J.-H. Direct and indirect reduction of Cr(VI) by fermentative Fe(III)-reducing Cellulomonas sp. strain Cellu-2a. J. Microbiol. Biotechnol. 2021, 31, 1519-1525. [CrossRef]

22. Stookey, L.L. Ferrozine-A new spectrophotometric reagent for iron. Anal. Chem. 1970, 42, 779-781. [CrossRef]

23. Frensemeier, L.M.; Büter, L.; Vogel, M.; Karst, U. Investigation of the oxidative transformation of roxarsone by electrochemistry coupled to hydrophilic interaction liquid chromatography/mass spectrometry. J. Anal. Atoms. Spectrom. 2017, 32, 153-161. [CrossRef]

24. Peretyazhko, T.; Zachara, J.M.; Heald, S.M.; Kukkadapu, R.K.; Liu, C.; Plymale, A.E.; Resch, C.T. Reduction of Tc(VII) by Fe(II) sorbed on Al (hydr)oxides. Environ. Sci. Technol. 2008, 42, 5499-5506. [CrossRef] [PubMed]

25. Cortinas, I.; Field, J.A.; Kopplin, M.; Garbarino, J.R.; Gandolfi, A.J.; Sierra-Alvarez, R. Anaerobic biotransformation of roxarsone and related N-substituted phenylarsonic acids. Environ. Sci. Technol. 2006, 40, 2951-2957. [CrossRef]

26. Moody, J.P.; Williams, R.T. The metabolism of 4-hydroxy-3-nitrophenylarsonic acid in hens. Food Cosmet. Toxicol. 1964, 2, 707-715. [CrossRef]

27. Yang, Z.; Peng, H.; Lu, X.; Liu, Q.; Huang, R.; Hu, B.; Kachanoski, G.; Zuidhof, M.J.; Le, X.C. Arsenic metabolites, including $\mathrm{N}$-acetyl-4-hydroxy-m-arsanilic acid, in chicken litter from a roxarsone-feeding study involving 1600 chickens. Environ. Sci. Technol. 2016, 50, 6737-6743. [CrossRef] 